\title{
GENETICAL VARIATION FOR ENZYME ACTIVITY IN A POPULATION OF DROSOPHILA MELANOGASTER
}

\section{DOMINANCE RELATIONSHIPS FOR ALCOHOL DEHYDROGENASE ACTIVITY}

\author{
A. J. BIRLEY and B. W. BARNES
}

Department of Genetics, University of Birmingham, P.O. Box 363, Birmingham B15 2TT, England

Received 1.ii.75

\begin{abstract}
SUMMARY
Four inbred lines, two homozygous $A d h^{S / S}$ and two homozygous $A d h^{F / F}$, were extracted from a laboratory cage population of Drosophila melanogaster and crossed in all combinations. Directional dominance for low ADH activity was present and confined to $A d h^{F / S}$ heterozygotes. The remaining genetical differences between the four lines for $\mathrm{ADH}$ activity were due to additive genetical variation. The frequency of the $A d h^{S}$ allele in the population was 0.89. The observed directional dominance for low ADH activity in $A d h^{F / S}$ heterozygotes corresponded to the general direction of selection for $\mathrm{ADH}$ activity within the population.
\end{abstract}

\section{INTRODUCTION}

GENETICAL variation has been demonstrated for $\mathrm{ADH}$ activity in a sample of inbred $A d h^{S / S}$ lines which had been extracted from a laboratory cage population of Drosophila melanogaster (Birley and Barnes, 1973). The inheritance of activity in two homozygous $A d h^{S / S}$ lines with differing activities was subsequently investigated and found to be under additive genetical control with the $\mathrm{X}$ chromosome having a significant effect (Barnes and Birley, 1975). In this study we have investigated some aspects of the inheritance of $\mathrm{ADH}$ activity in crosses between $A d h^{F / F}$ and $A d h^{S / S}$ lines.

\section{Materials AND Methods}

Nineteen independently derived inbred lines were extracted from the laboratory cage population "Texas". From amongst the 17 lines which were homozygous $A d h^{S / S}$, two lines $\mathrm{P}_{15}$, the line with the highest $\mathrm{ADH}$ activity, and $\mathrm{P}_{25}$, the line with the lowest $\mathrm{ADH}$ activity, were selected for this study together with the two lines homozygous $A d h F / F, \mathrm{P}_{6}$ and $\mathrm{P}_{19}$. These four inbred lines were crossed in all combinations, i.e. a diallel set of crosses. The families were raised in a single randomised block at $25^{\circ} \mathrm{C}$.

Alcohol dehydrogenase activity was measured using the method described by Birley and Barnes (1973). Four female flies were assayed individually from each of the 16 families on three separate occasions (blocks). In all a total of 192 flies were assayed.

\section{Results}

The metric specific activity $\left(\frac{1}{T} \times \frac{1}{P} \times 100\right)$ which has been used in 
previous papers (Birley and Barnes, 1973; Barnes and Birley, 1975) is preferable to activity $\left(\frac{1}{T} \times 100\right)$ only if the total soluble protein $(P)$ consistently reflects the amount of $\mathrm{ADH}$ protein. This assumption may not be justified as there is evidence of genetic variation for soluble protein in

\section{TABLE 1}

Alcohol dehydrogenase activity of parents and $F_{1}$ 's

\begin{tabular}{rrccc} 
& \multicolumn{4}{c}{ Line } \\
\cline { 2 - 5 } 25 & 25 & 15 & 19 & 6 \\
15 & $9 \cdot 42$ & $11 \cdot 78$ & $18 \cdot 20$ & $14 \cdot 09$ \\
19 & $17 \cdot 30$ & $17 \cdot 48$ & $20 \cdot 08$ & $15 \cdot 00$ \\
6 & $12 \cdot 61$ & $18 \cdot 79$ & $36 \cdot 24$ & $32 \cdot 08$ \\
& & & &
\end{tabular}

TABLE 2

Analysis of variance of diallel table

\begin{tabular}{|c|c|c|c|}
\hline Item & d.f. & M.S. & $\mathbf{P}$ \\
\hline $\begin{array}{l}a \\
F / F \text { v.S/S } \\
15 \text { v. } 25 \\
60.19\end{array}$ & $\begin{array}{l}3 \\
1 \\
1 \\
1\end{array}$ & $\begin{array}{l}108 \cdot 64 \\
258 \cdot 99 \\
31 \cdot 13 \\
35 \cdot 78\end{array}$ & $\begin{array}{l}<0.1 \% \\
<0.1 \% \\
<0.1 \% \\
<0.1 \%\end{array}$ \\
\hline $\begin{array}{l}b \\
b_{1} \\
b_{2} \\
b_{8}\end{array}$ & $\begin{array}{r}6 \\
1 \\
3 \\
2\end{array}$ & $\begin{array}{l}3 \cdot 40 \\
5 \cdot 33 \\
0 \cdot 99 \\
6 \cdot 07\end{array}$ & $\begin{array}{c}1-0 \cdot 1 \% \\
5-1 \% \\
\text { n.s. } \\
1-0 \cdot 1 \%\end{array}$ \\
\hline$c$ & 3 & 1.44 & n.s. \\
\hline$d$ & 3 & $0 \cdot 30$ & n.s. \\
\hline Blocks $(B)$ & 2 & $1 \cdot 12$ & n.s. \\
\hline $\begin{array}{l}B \times a \\
B \times b_{1} \\
B \times b_{2} \\
B \times b_{3} \\
B \times C \\
B \times d\end{array}$ & $\begin{array}{l}6 \\
2 \\
6 \\
4 \\
6 \\
6\end{array}$ & $\begin{array}{l}0.56 \\
0.06 \\
1.51 \\
0.55 \\
0.88 \\
1 \cdot 19\end{array}$ & \\
\hline Pooled interactions & 30 & 0.90 & \\
\hline
\end{tabular}

crosses between lines 15 and 25 (Barnes and Birley, 1975), of which ADH protein would constitute only a small part. If this is the case, then the reliability of specific activity becomes much reduced. For this reason the analysis presented below is concerned with activity.

The results, summed over blocks, are shown in table 1 and the analysis of variance of diallel tables (Hayman, 1954) is given in table 2. The main items in the analysis have all been tested against a pooled error mean square with 30 degrees of freedom as the individual error variances were homogeneous, $\chi^{2}(5)=5 \cdot 20$. This shows that there are no genotype-environment 
interactions. The analysis shows that there is significant additive variation between the lines ( $a$ item) together with significant non-additive variation ( $b$ item). A partition of the $a$ sum of squares shows genetical differences in activity between the two electrophoretic morphs, and between lines of the same morph, i.e. 15 v. 25 and 6 v. 19 . On the assumption that there are no non-allelic interactions - we will test this later-the non-additive variation is attributed to dominance. The significant $b_{1}$ item shows that on average the $F_{1}$ mean differs from the mean of the parents and we can see from an inspection of the data (table 1 ) that dominance is for low activity.

Furthermore, the significant $b_{3}$ item shows that the dominance effects are specific to certain crosses. This is apparent from the percentage potence values given in table 3 .

Large values are associated with $A d h^{F / S}$ heterozygotes and dominance is most pronounced in crosses involving line 15. Although we are unable to test individually the significance of the values in table 3 , we have already shown (Barnes and Birley, 1975) that in crosses between lines 15 and 25

TABLE 3

Percentage potence values

\begin{tabular}{rcccc} 
& \multicolumn{4}{c}{} \\
25 & $\overbrace{25}$ & 15 & 19 & 6 \\
15 & - & $-10 \cdot 6$ & $-20 \cdot 0$ & -16.9 \\
19 & - & - & $-57 \cdot 4$ & -116.5 \\
6 & - & - & - & $3 \cdot 1$
\end{tabular}

there is no evidence for dominance. The $A d h^{F / S}$ heterozygotes are consistent in showing dominance for low activity. The analysis also shows that there are no significant reciprocal differences $(c$ and $d)$ or differences between occasions (blocks).

The variance-covariance analysis of Jinks $(1954,1956)$ allows us to test whether the non-additive genetic variation results from dominance or from non-allelic interactions. The test depends on calculating the variance of each array $(V r)$ and the covariance of the array on the non-recurrent parent $(W r)$. We can see from table 4 that the non-additive genetic variation, demonstrated by the differences between the $(W r+V r)$ values, can be attributed solely to dominance variation as the $(W r-V r)$ values do not differ significantly over arrays.

TABLE 4

Analysis of variance of $(\mathrm{Wr}+\mathrm{Vr})$ and of $(\mathrm{Wr}-\mathrm{Vr})$

\begin{tabular}{lcccccc}
\multicolumn{1}{c}{ Item } & d.f. & $\overbrace{\text { M.S. }}$ & $\mathrm{P}$ & & $\overbrace{\text { M.S. }}^{(W r+V r)}$ & $\mathrm{P}$ \\
Arrays & 3 & 124.97 & $6 \%$ & 0.44 & n.s. \\
Blocks & 2 & 40.45 & n.s. & 1.44 & n.s. \\
Arrays $\times$ Blocks & 6 & 28.18 & & 1.07 &
\end{tabular}


Further information on the nature of the dominance between the lines may be obtained from the relationship between $W r$ and $V r$ shown in fig. 1 . The $W r$ and $V r$ values have each been corrected for the respective environmental component and then averaged over the three blocks. The slope of the regression line does not differ from one, and the intercept is positive showing incomplete dominance. Lines 15 and 25 contain most dominant alleles as these points lie nearest to the origin while 6 and 19 contain most recessive alleles. We should recall that the activities of 15 and 25 and of

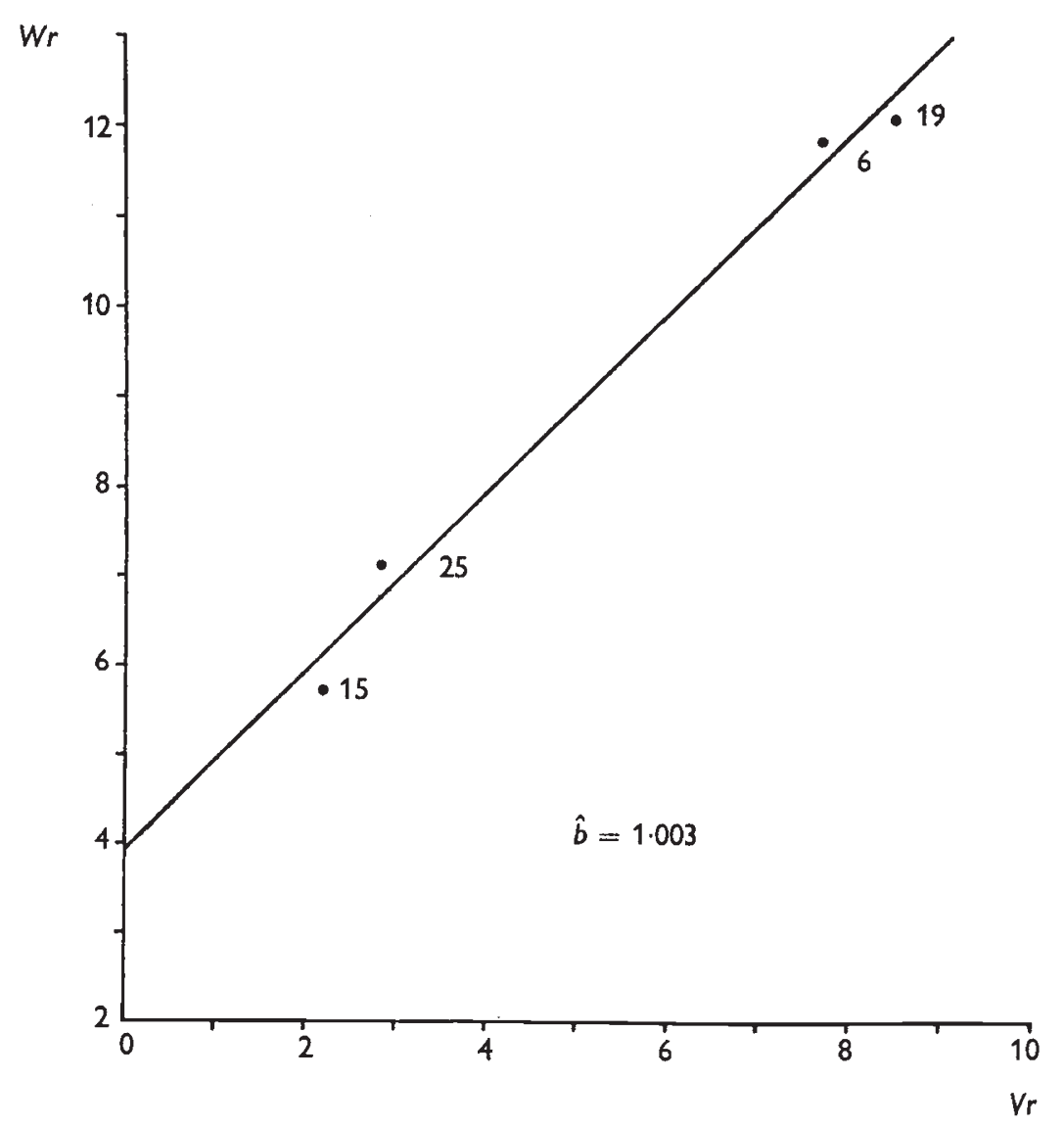

FIG. 1.-Relationship between the covariance of arrays $(W r)$ and the variance of arrays $(V r)$.

6 and 19 differ significantly. The direction of dominance can be obtained by examining the relationship between $(W r+V r)$ and the mean of the common parent. The dominant parents have low activity while the recessive parents have high activity. We conclude that there is directional dominance for low activity-although the association is not complete since line 25 which has the lowest activity is not the most dominant.

\section{Discussion}

In this experiment dominance for low activity was apparent in crosses between the $A d h^{S / S}$ and $A d h^{F / F}$ lines. The frequency of the $A d h^{S}$ allele 
in the population was 0.89 and the $A d h^{S / S}$ lines are less active than the $A d h^{F / F}$ lines (Birley and Barnes, 1973). Previous work on lines extracted from a number of other populations also showed the $A d h^{F / F}$ homozygotes to be more active than the $A d h^{S / S}$ homozygotes (Gibson, 1970; Gibson and Miklovich, 1971; Day et al., 1974 $a$ and $b$ ). Day et al, (1974b) further showed that in lines derived from the Kaduna population the molecular activity of $\mathrm{ADH} \mathrm{F}$ is approximately twice that of $\mathrm{ADH} \mathrm{S}$ and a similar number of $\mathrm{ADH}$ molecules was produced by the two genotypes.

The ADH molecule has been reported to be a dimer and the $A d h^{F / S}$ heterozygote possesses unique hybrid enzymes (Ursprung and Leone, 1965). The enzyme also exists in different conformations and interconversion of the conformers can be accomplished, for example, by changes in the in vitro concentration of NAD (Jacobson et al., 1972). Furthermore, Day and Needham (1974) have shown that two conformers (ADH-5 and ADH-3) extracted from Drosophila melanogaster homozygous for the $A d h^{S}$ allele differ in their specific activities. This situation lends itself to one whereby allosteric properties of the enzyme could result in dominance for enzyme activity; such possibilities are further discussed by Fincham (1972).

Gibson and Miklovich (1971) reported ADH specific activity measurements for lines which had been independently extracted from a population of Drosophila melanogaster maintained in Professor J. A. Beardmore's department at the University College of Swansea, Wales, U.K. This population originated from a sample of inseminated females collected in Groningen (the Netherlands) and subsequently maintained as a laboratory cage population for 3 years. The measurements were made at $25^{\circ} \mathrm{C}$ upon four lines, two of which were $A d h^{F / F}$ and two $A d h^{S / S}$ together with the $A d h^{F / S}$ heterozygotes. The percentage potence values are shown below.

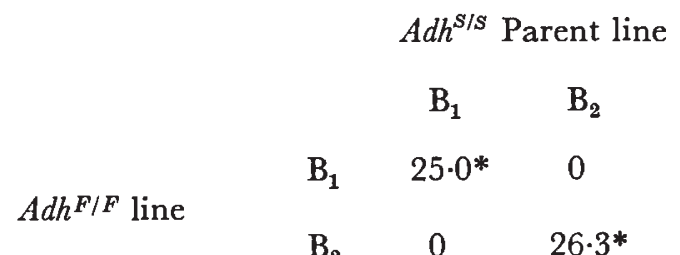

* Heterozygote enzyme activity significantly different from the mid-parental value (Gibson and Miklovich, 1971).

The direction of dominance is for high $\mathrm{ADH}$ activity and in the population from which these lines were extracted the frequency of the $A d h^{F}$ allele was 0.84 (Birley, unpublished). Dominance is again incomplete and restricted to specific crosses.

Although the data are limited we can see that in the two populations that have been studied dominance for $\mathrm{ADH}$ activity is for the common allele. Ward and Hebert (1972) have shown that other loci can modify ADH activity and similarly Barnes and Birley (1975) have established a significant effect of the $\mathrm{X}$ chromosome. The differing dominance relationship between $A d h^{S}$ and $A d h^{F}$ in the two populations may be interpreted, therefore, as resulting from a modification process of the type proposed by Fisher (1930). Alternatively, there may be differences between the Adh 
alleles from the two populations which are undetetectable electrophoretically and which give rise to different dominance relationships.

Acknowledgements.-We wish to thank Dr Henry Lun Kwok Chan for assistance with the experimental work.

\section{REFERENCES}

BARNES, B. W., AND BIRLEY, A. J. 1975. Genetical variation for enzyme activity in a population of Drosophila melanogaster. II. Aspects of the inheritance of alcohol dehydrogenase activity in $A d h^{S / S}$ flies. Heredity $35,115-119$.

BIRLEY, A. J., AND BARNES, B. W. 1973. Genetical variation for enzyme activity in a population of Drosophila melanogaster. I. Extent of the variation for alcohol dehydrogenase activity. Heredity, 31, 413-416.

DAy, T. H., hillier, P. C., AND Clarke, B. 1974a. Properties of genetically polymorphic isozymes of alcohol dehydrogenase in Drosophila melanogaster. Biochem. Genet., 11, 141-153.

DAY, T. H., HILlier, P. C., AND CLARKE, B. $1974 b$. The relative quantities and catalytic activities of enzymes produced by alleles at the alcohol dehydrogenase locus in Drosophila melanogaster. Biochem. Genet., 11, 155-165.

Day, T. H., AND NEEDhaM, L. 1974. Properties of alcohol dehydrogenase isozymes in a strain of Drosophila melanogaster homozygous for the Adh-Slow allele. Biochem. Genet., $11,167-175$.

FINCHAM, J. R. s. 1972. Heterozygous advantage as a likely general basis for enzyme polymorphisms. Heredity, 28, 387-391.

Fisher, R. A. 1930. The Genetical Theory of Natural Selection. Clarendon Press, Oxford.

GIBson, J. 1970. Enzyme flexibility in Drosophila melanogaster. Nature, 227, 959-960.

GIBsON, J., AND MIKLovich, R. 1971. Modes of variation in alcohol dehydrogenase in Drosophila melanogaster. Experientia, 27, 99-100.

hayman, B. I. 1954. The analysis of variance of diallel crosses. Biometrics, 10, 235-244.

JACOBSON, K. B., MURPHY, J. B., KNOPP, J. A., AND ORTIZ, J. R. 1972. Multiple forms of Drosophila alcohol dehydrogenase. III. Conversion of one form to another by nicotinamide adenine dinucleotide or acetone. Arch. Biochem. Biophys., 149, 22-35.

JiNKs, J. L. 1954. The analysis of continuous variation in a diallel cross of Nicotiana rustica varieties. Genetics, 39, 767-788.

JiNKs, J. L. 1956. The $\mathrm{F}_{2}$ and backcross generations from a set of diallel crosses. Heredity, $10,1-30$.

URSPRUNG, H., AND LEONE, J. 1965. Alcohol dehydrogenases: a polymorphism in Drosophila melanogaster. J. Exp. Zool., 160, 147-154.

WARD, R. D., AND HEBERT, P. D. N. 1972. Variability of alcohol dehydrogenase activity in a natural population of Drosophila melanogaster. Nature, New Biology, 236, 243-244. 